\title{
Dieta com alto teor de gordura e desempenho de tourinhos de grupos genéticos diferentes em confinamento
}

\author{
Andréa Roberto Duarte Lopes Souza ${ }^{(1)}$, Sérgio Raposo de Medeiros ${ }^{(2)}$, Maria da Graça Morais ${ }^{(1)}$, \\ Maurílio Massaharu Oshiro(1) e Roberto Augusto de Almeida Torres Júnior(2)
}

\begin{abstract}
(1)Universidade Federal de Mato Grosso do Sul, Faculdade de Medicina Veterinária e Zootecnia, Avenida Senador Filinto Müller, № 2.443, Caixa Postal 549, CEP 79070-900 Campo Grande, MS. E-mail: andreardl_dagher@yahoo.com.br, morais.mariazinha@gmail.com, maurilio.oshiro@yahoo.com.br (2)Embrapa Gado de Corte, BR 262, Km 4, Caixa Postal 154, CEP 79002-970 Campo Grande, MS. E-mail: sergio@cnpgc.embrapa.br, rtorres@cnpgc.embrapa.br
\end{abstract}

Resumo - O objetivo deste trabalho foi avaliar o desempenho em confinamento de tourinhos de quatro grupos genéticos distintos tratados com dietas com diferentes teores de gordura. Foram utilizados nove animais Nelore, nove Caracu, dez $1 / 2$ Caracu 1/4 Angus 1/4 Nelore e dez 1/2 Red Angus 1/4 Caracu 1/4 Nelore, com massa corporal inicial de $227 \pm 33 \mathrm{~kg}$ e dez meses de idade, distribuídos aleatoriamente em dois tratamentos nutricionais: baixo teor de gordura (3,15\% de extrato etéreo) e alto teor de gordura ( $7,28 \%$ de extrato etéreo). A ingestão de matéria seca (IMS) foi quantificada durante 208 dias e as pesagens dos animais foram realizadas a cada 28 dias. Os animais alimentados com as dietas de alto e de baixo teor de gordura apresentaram resultados similares de ganho médio diário de peso $(1,511 \times 1,487 \mathrm{~kg}$ por dia, respectivamente) e de eficiência alimentar (194x180 g de ganho por quilograma de MS ingerida, respectivamente); a IMS, em percentagem do peso vivo, foi menor nos animais alimentados com dieta de alto teor de gordura (2,25x2,40, respectivamente). Os animais cruzados apresentaram maior ganho de massa corporal e IMS que os Nelore. A dieta com alto teor de gordura pode ser utilizada em confinamento para melhorar o desempenho de tourinhos 1/2 Caracu 1/4 Angus 1/4 Nelore, pois é eficiente para reduzir a ingestão de matéria seca e não prejudica o ganho de massa corporal dos animais.

Termos para indexação: Bos taurus, Bos indicus, cruzamento, ingestão de matéria seca, grão de soja, lipídio.

\section{High-fat diet and feedlot performance of bullocks of different genetic groups}

\begin{abstract}
This work aimed to evaluate the feedlot performance of bullocks of four distinct genetic groups receiving diets with different levels of fat. Nine Nelore; nine Caracu; ten 1/2 Caracu 1/4 Angus 1/4 Nelore and ten $1 / 2$ Red Angus $1 / 4$ Caracu $1 / 4$ Nelore bullocks, with a mean initial weight of $227 \pm 33 \mathrm{~kg}$ and ten months of age, were randomly assigned to two nutritional treatments and fed either with low-fat (3.15\% ether extract) or high-fat diet (7.28\% ether extract). Dry matter intake (DMI) was quantified during 208 days and the animals were weighed every 28 days. Animals fed with the high-fat and the low-fat diet presented similar results for average daily weight gain $\left(1.511 \times 1.487 \mathrm{~kg} \mathrm{day}^{-1}\right.$, respectively) and feed efficiency $(194 \mathrm{x} 180 \mathrm{~g}$ gain per $\mathrm{kg}$ DMI, respectively); the DMI, expressed as live weight percentage, was lower in animals receiving high-fat diet $(2.25 \times 2.40$, respectively). Crossbred animals presented greater daily weight gain and DMI than Nelore. The high-fat diet can be used in feedlot to improve the performance of $1 / 2$ Caracu $1 \frac{1}{4}$ Angus $1 / 4$ Nelore bullocks, since it is efficient in reducing the DMI without compromising weight gain.
\end{abstract}

Index terms: Bos taurus, Bos indicus, crossbreed, dry matter intake, raw soybean, lipid.

\section{Introdução}

A inclusão de gordura na dieta animal não deve ultrapassar $6 \%$ de extrato etéreo na matéria seca (Mir et al., 2001), a fim de evitar efeitos deletérios à digestão dos alimentos e o comprometimento do consumo de matéria seca (Jenkins, 1993).

Alguns trabalhos (Felton \& Kerley, 2004a, $2004 \mathrm{~b}$; Jordan et al., 2006) mostram que esse limite é bastante conservador. Isto porque produtores têm observado desempenhos satisfatórios dos animais ao fornecer níveis acima de $6 \%$ de extrato etéreo nas dietas. Assim, a avaliação de dietas com teores mais elevados de extrato etéreo quanto a seus efeitos sobre o desempenho de bovinos de corte confinados é pertinente.

Além da dieta adequada, os diversos genótipos disponíveis (Bos taurus, Bos indicus e seus mestiços) apresentam desempenhos distintos em confinamento. Pesquisas têm evidenciado que animais mestiços 
apresentam melhores desempenhos em confinamento em relação aos puros (Euclides Filho et al., 2002; Ferreira et al., 2004; Menezes \& Restle, 2005). Porém, as diferenças entre alguns grupos genéticos envolvendo raças taurinas adaptadas, zebuínas e seus cruzamentos em dietas de alto desempenho ainda precisam ser mais bem entendidas, o que permitirá a escolha da raça adequada para cada sistema de produção.

O objetivo deste trabalho foi avaliar o desempenho em confinamento de tourinhos de grupos genéticos distintos, alimentados com dietas de diferentes teores de gordura.

\section{Materiais e Métodos}

O experimento foi conduzido na Embrapa Gado de Corte, em Campo Grande, MS, de agosto de 2006 a abril de 2007. Foram confinados 40 animais inteiros de quatro grupos genéticos (dez animais em cada um), com idade média inicial de $10 \pm 2$ meses e $227 \pm 33 \mathrm{~kg}$ de peso vivo.

Não foi possível concluir a avaliação de dois animais (um Nelore e um Caracu) que, além de não terem atingido grau de acabamento (espessura de gordura mínima de $3 \mathrm{~mm}$, obtida por ultrassonografia) no final do experimento, apresentaram desempenho bem inferior ao dos demais. Após análise dos dados pelo SAS (SAS Institute, 2002), verificou-se que ambos são "outliers". Assim, o número de animais avaliados foi: nove animais Nelore, dez $1 / 2$ Caracu $1 / 4$ Angus $1 / 4$ Nelore (C-A-N), dez $1 / 2$ Red Angus $1 / 4$ Caracu $1 / 4$ Nelore (RA-C-N) e nove Caracu.
Os animais foram confinados em baias individuais ( $2 \times 8 \mathrm{~m})$ cobertas e com piso de concreto, providas de cocho $(2 \times 0,8 \mathrm{~m})$ e bebedouro automático de alumínio fundido $(0,3 \mathrm{~m}$ de diâmetro, $0,1 \mathrm{~m}$ de altura e capacidade para $3 \mathrm{~L}$ ), e distribuídos em dois tratamentos nutricionais (baixo gordura e alto teor de gordura). O tratamento com baixo teor de gordura continha 20 animais (cinco Caracu, cinco C-A-N, cinco RA-C-N e cinco Nelore) e o de alto teor de gordura, 18 animais (quatro Caracu, cinco C-A-N, cinco RA-C-N e quatro Nelore).

$\mathrm{O}$ tratamento com baixo teor de gordura consistia em dieta com $3,15 \%$ de extrato etéreo (EE) em base de matéria seca (MS) e o tratamento com alto teor de gordura, em dieta com 7,28\% de EE. A fonte de gordura utilizada foi o grão de soja moído. As dietas eram isoproteicas, com valores determinados de 15,99 e $14,69 \%$ de proteína bruta (PB), e isoenergéticas, com 72,8 e $71,7 \%$ de nutrientes digestíveis totais (NDT), para as dietas com baixo e alto teor de gordura, respectivamente.

As dietas continham, em média, $26 \%$ de silagem de sorgo como volumoso e $74 \%$ de concentrado em base de MS (Tabela 1), e foram formuladas utilizandose o software RLM 3.0, desenvolvido por Lanna et al. (2005). As dietas formuladas previam ganhos de $1,5 \mathrm{~kg}$ por dia.

No início do experimento, os animais foram pesados, vermifugados e distribuídos aleatoriamente nas baias individuais. O período de adaptação foi de 28 dias, destinados ao processo de adaptação dos animais às

Tabela 1. Proporção (\%) dos ingredientes e composição bromatológica das dietas experimentais, com base na matéria seca ${ }^{(1)}$.

\begin{tabular}{|c|c|c|}
\hline Ingredientes & Dieta com baixo teor de gordura & Dieta com alto teor de gordura \\
\hline Silagem de sorgo & 28,67 & 24,82 \\
\hline Milho - grão seco & 36,86 & 36,48 \\
\hline Soja - grão moído & 1,90 & 17,60 \\
\hline Farelo de soja $45 \%$ & 16,39 & 2,09 \\
\hline Casca de soja & 14,48 & 17,24 \\
\hline Suplemento mineral ${ }^{(2)}$ & 0,70 & 0,72 \\
\hline Calcário calcítico & 1,00 & 1,04 \\
\hline \multicolumn{3}{|l|}{ Composição das dietas } \\
\hline Matéria seca $(\%)$ & 54,63 & 54,79 \\
\hline Carboidratos não fibrosos (g $100 \mathrm{~g}^{-1}$ de $\left.\mathrm{MS}\right)$ & 36,96 & 32,04 \\
\hline Extrato etéreo (g $100 \mathrm{~g}^{-1}$ de MS) & 3,15 & 7,28 \\
\hline Proteína bruta (g $100 \mathrm{~g}^{-1}$ de MS) & 15,99 & 14,69 \\
\hline Fibra em detergente neutro (g $100 \mathrm{~g}^{-1}$ de $\mathrm{MS}$ ) & 38,85 & 41,57 \\
\hline Fibra em detergente ácido (g $100 \mathrm{~g}^{-1}$ de MS) & 25,79 & 28,07 \\
\hline Nitrogênio ligado à fibra em detergente neutro (g $100 \mathrm{~g}^{-1}$ de $\left.\mathrm{MS}\right)$ & 0,97 & 1,03 \\
\hline Nitrogênio ligado à fibra em detergente ácido (g $100 \mathrm{~g}^{-1}$ de MS) & 0,76 & 0,86 \\
\hline Matéria mineral (g $100 \mathrm{~g}^{-1}$ de MS) & 6,02 & 5,45 \\
\hline Lignina (g $100 \mathrm{~g}^{-1}$ de MS) & 2,70 & 3,17 \\
\hline Nutrientes digestíveis totais $(\%)^{(3)}$ & 72,78 & 71,7 \\
\hline
\end{tabular}

$\mathrm{Mn}, 400 \mathrm{mg} \mathrm{kg}^{-1}$; Se, 2,00 mg kg-1; Zn, $800 \mathrm{mg} \mathrm{kg}^{-1}$. (3)Estimado pela fórmula de Weiss et al. (1992). 
instalações e às dietas experimentais. Na primeira semana, os animais receberam somente silagem; na segunda semana, silagem mais $30 \%$ de concentrado; na terceira semana, silagem mais $50 \%$ de concentrado e, na quarta semana, as dietas experimentais (25\% silagem e $75 \%$ concentrado).

Após o período de adaptação, os animais foram pesados em jejum. O consumo e o ganho de massa corporal diários foram quantificados durante 208 dias de experimento. Os animais receberam alimentação duas vezes ao dia: $40 \%$ da dieta pela manhã (às $8 \mathrm{~h}$ ) e $60 \%$ à tarde (às 14h). Os ingredientes dos concentrados foram triturados, misturados e armazenados na fábrica de ração, em equipamento da marca Osório, com triturador modelo TO-3, rosca transportadora, caçamba de pesagem, misturador e silo pulmão. A silagem e o concentrado foram batidos, no momento do arraçoamento, por uma misturadora acoplada a um trator.

As sobras eram coletadas em baldes e pesadas diariamente pela manhã, em balança eletrônica de piso (marca Toledo, modelo 2124, com capacidade para $100 \mathrm{~kg}$ ), e descartadas. $\mathrm{O}$ consumo foi ajustado diariamente de acordo com a quantidade de sobras, que eram mantidas próximas de $10 \%$ do que era oferecido ao dia, para caracterizar o consumo ad libitum.

As dietas ofertadas foram amostradas semanalmente. Todas as amostras foram armazenadas em congelador $\left(-20^{\circ} \mathrm{C}\right)$ e posteriormente descongeladas, secas em estufa de ventilação forçada de ar a $55^{\circ} \mathrm{C}$ durante 48 horas, e trituradas em moinho tipo Wiley, utilizando-se peneiras com malhas de $1 \mathrm{~mm}$ para as análises bromatológicas.

As análises bromatológicas das dietas foram baseadas nos nutrientes exigidos para estimar NDT, segundo equação proposta por Weiss et al. (1992). Foram analisados os teores de fibra em detergente neutro (FDN), nitrogênio ligado à fração FDN (N-FDN), fibra insolúvel em detergente ácido (FDA), nitrogênio ligado à fração FDA (N-FDA), lignina em ácido sulfúrico (LIG), PB, $\mathrm{EE}$, matéria mineral $(\mathrm{MM})$ e $\mathrm{MS}$, a $105^{\circ} \mathrm{C}(\mathrm{AOAC}$ International, 1990) (Tabela 1).

As pesagens dos animais foram realizadas a cada 28 dias, após jejum alimentar de 24 horas e jejum hídrico de 16 horas. Quando apresentavam $3 \mathrm{~mm}$ de espessura de gordura subcutânea (medidas obtidas por meio de imagens de ultrassom) e aproximadamente $450 \mathrm{~kg}$, os animais eram abatidos.

$\mathrm{O}$ delineamento experimental foi inteiramente casualizado, em arranjo fatorial $2 \mathrm{x} 4$ (duas dietas $\mathrm{x}$ quatro grupos genéticos). A análise de variância foi feita pelo procedimento de modelos lineares gerais do SAS (SAS Institute, 2002). No modelo, foram incluídas as dietas e os grupos genéticos como efeitos principais, além da interação dos fatores (dieta $\mathrm{x}$ grupo genético). O peso vivo inicial foi utilizado como co-variável. A comparação entre as médias dos tratamentos, os grupos genéticos e a interação dos fatores foi realizada pelo teste de Tukey, a 5\% de probabilidade.

\section{Resultados e Discussão}

Não houve efeito significativo da interação dieta $\mathrm{x}$ grupo genético sobre peso vivo final, espessura de gordura, ingestão de matéria seca e eficiência alimentar. Desse modo, tais fontes de variação foram discutidas separadamente. Foi detectado efeito da interação sobre ganho médio diário (Tabela 2).

Ao estudar os efeitos das dietas dentro de cada grupo genético, observou-se que os animais C-A-N alimentados com a dieta com alto teor de gordura apresentaram ganho médio diário de peso (GMD)

Tabela 2. Peso vivo inicial e final, espessura de gordura, período de confinamento, ingestão de matéria seca, ganho médio diário e eficiência alimentar de bovinos de corte dos grupos genéticos Caracu, $1 / 2$ Caracu $1 / 4$ Angus $1 / 4$ Nelore (C-A-N), $1 / 2$ Red Angus $1 / 4$ Caracu $1 / 4$ Nelore (RA-C-N) e Nelore alimentados com dietas com baixo e alto teor de gordura ${ }^{(1)}$.

\begin{tabular}{|c|c|c|c|c|c|c|c|c|c|c|}
\hline \multirow[t]{2}{*}{ Variáveis } & \multicolumn{2}{|c|}{ Caracu } & \multicolumn{2}{|c|}{ C-A-N } & \multicolumn{2}{|c|}{ RA-C-N } & \multicolumn{2}{|c|}{ Nelore } & \multirow[t]{2}{*}{ EPM } & \multirow[t]{2}{*}{$P$} \\
\hline & $\begin{array}{c}\text { Baixa } \\
\text { gordura }\end{array}$ & $\begin{array}{c}\text { Alta } \\
\text { gordura }\end{array}$ & $\begin{array}{c}\text { Baixa } \\
\text { gordura }\end{array}$ & $\begin{array}{c}\text { Alta } \\
\text { gordura }\end{array}$ & $\begin{array}{c}\text { Baixa } \\
\text { gordura }\end{array}$ & $\begin{array}{c}\text { Alta } \\
\text { gordura }\end{array}$ & $\begin{array}{c}\text { Baixa } \\
\text { gordura }\end{array}$ & $\begin{array}{c}\text { Alta } \\
\text { gordura }\end{array}$ & & \\
\hline Peso vivo inicial (kg) & 224 & 213 & 262 & 269 & 228 & 234 & 194 & 195 & 21 & - \\
\hline Peso vivo final $(\mathrm{kg})$ & 478 & 466 & 473 & 496 & 483 & 458 & 409 & 433 & 33 & 0,29 \\
\hline Espessura de gordura (mm) & 3,28 & 4,47 & 3,40 & 3,45 & 4,35 & 3,32 & 4,63 & 4,83 & 33 & 0,13 \\
\hline Período de confinamento (dias) & 172 & 197 & 147 & 122 & 139 & 130 & 180 & 197 & 0,98 & 0,22 \\
\hline Ingestão de matéria seca $\left(\mathrm{kg} \mathrm{dia}^{-1}\right)$ & 8,433 & 7,486 & 8,082 & 8,566 & 9,433 & 8,136 & 7,116 & 6,994 & 28 & 0,12 \\
\hline Ingestão de matéria seca (\% PV) & 2,40 & 2,18 & 2,25 & 2,28 & 2,65 & 2,36 & 2,31 & 2,19 & 0,86 & 0,43 \\
\hline Ganho médio diário (GMD, $\left.\mathrm{kg} \mathrm{dia}^{-1}\right)$ & 1,459 & 1,275 & $1,508 \mathrm{~b}$ & $1,881 \mathrm{a}$ & 1,830 & 1.727 & 1,152 & 1,164 & 0,23 & 0,009 \\
\hline Eficiência alimentar (kg GMD por kg MS) & 0,176 & 0,179 & 0,171 & 0,203 & 0,197 & 0,212 & 0,180 & 0,183 & 0,18 & 0,47 \\
\hline
\end{tabular}

${ }^{(1)}$ Médias seguidas de letras iguais na mesma linha não diferem entre si, pelo teste de Tukey, a 5\% de probabilidade. EPM, erro padrão da média; $\mathrm{P}$, significância estatística. 
significativamente superior ao dos animais C-A-N alimentados com a dieta de baixo teor de gordura. Esse maior GMD dos animais C-A-N alimentados com a dieta com alto teor de gordura e a ingestão de matéria seca (IMS), similar à dos animais C-A-N do tratamento com baixo teor de gordura, podem estar associados a melhorias na eficiência energética de síntese de tecidos e à redução do incremento calórico.

O aumento do consumo e absorção de ácidos graxos insaturados (AGI) de cadeia longa permite melhorias na eficiência metabólica das reações de anabolismo no tecido adiposo, pois, por estarem prontamente disponíveis para deposição, há redução do custo energético da síntese de gordura a partir de ácidos graxos de cadeia curta, como acetato e butirato. A síntese de gorduras a partir de ácidos graxos de cadeia média e curta requer a utilização de glicose como fornecedora de agentes redutores (NADPH), por meio do ciclo das pentoses (Chilliard, 1993).

O fornecimento de grãos de soja, fonte rica em AGI de cadeia longa, pode ter diminuído a utilização da glicose como fonte de energia na síntese de gordura e aumentado sua disponibilidade para outros processos metabólicos. Da mesma forma, poderia estar ocorrendo economia de energia pelo fato de a oxidação direta de ácidos graxos ser $10 \%$ mais eficiente que a oxidação do acetato (Palmquist, 1994).

Assim, os animais C-A-N do tratamento de alta gordura podem ter sido capazes de manter a ingestão energética para mantença e, se houve redução do incremento calórico e melhorias na eficiência energética, o maior GMD observado pode ser resultado do aumento da disponibilidade de energia líquida para o ganho de peso.

Não foram detectadas diferenças significativas entre os tratamentos nutricionais quanto ao peso vivo final, à espessura de gordura e aos dias de confinamento. Os animais do tratamento com alto teor de gordura apresentaram menor IMS em percentagem do peso vivo (\% PV), em relação aos animais alimentados com dieta com baixo teor de gordura. Quando a IMS foi expressa em kg dia ${ }^{-1}$, não foram observadas diferenças significativas entre as médias dos tratamentos (Tabela 3).

A redução na IMS tem sido observada com a inclusão de elevados níveis de gorduras nas dietas de ruminantes (Felton \& Kerley, 2004a; Aferri et al., 2005; Jordan et al., 2006), porém, os mecanismos envolvidos nos resultados ainda não estão bem elucidados na literatura. É possível que, neste experimento, a redução da IMS esteja relacionada aos efeitos dos AGI sobre o centro de saciedade. O grão de soja é fonte rica em AGI (McNiven et al., 2004), e o maior aporte utilizado na dieta para elevar o teor de EE deve ter aumentado o fluxo de AGI para o intestino delgado (ID).

Em torno de $20 \%$ dos AGI ingeridos pelos ruminantes chegam ao ID sem sofrer bio-hidrogenação completa (Martinez Marín, 2007). Porém, o maior ou menor fluxo de AGI para o ID depende da fonte de gordura utilizada e da composição da dieta (Jordan et al., 2006). O maior aporte de AGI dietético, em conjunto com a taxa de passagem mais alta, e o menor $\mathrm{pH}$ associados às dietas com alta proporção de concentrado $(74 \%)$ predispõem a menores taxas de bio-hidrogenação (Martinez Marín, 2007), o que poderia ter contribuído para o aumento do fluxo de AGI parcialmente bio-hidrogenados para o ID.

Se houve maior disponibilidade de AGI para absorção no ID, pode ter ocorrido elevação desses metabólitos no sangue. De acordo com Obici et al. (2002), o aumento da concentração sérica de AGI ativa receptores do centro da saciedade localizados no hipotálamo, que inibem o apetite e reduzem o consumo de alimentos.

O aumento da concentração plasmática de ácidos graxos e a redução da IMS foram observados por

Tabela 3. Peso vivo inicial e final, espessura de gordura, período de confinamento, ingestão de matéria seca, ganho médio diário e eficiência alimentar de bovinos de corte confinados alimentados com dietas de baixo e de alto teor de gordura ${ }^{(1)}$.

\begin{tabular}{|c|c|c|c|c|}
\hline Variáveis & Baixo teor de gordura & Alto teor de gordura & EPM & $\mathrm{P}$ \\
\hline Peso vivo inicial (kg) & 227 & 228 & 21 & - \\
\hline Peso vivo final $(\mathrm{kg})$ & 461 & 463 & 33 & 0,85 \\
\hline Espessura de gordura (mm) & 3,92 & 4,02 & 0,98 & 0,76 \\
\hline Período de confinamento (dias) & 160 & 161 & 28 & 0,88 \\
\hline Ingestão de matéria seca $\left(\mathrm{kg} \mathrm{dia}^{-1}\right)$ & 8,265 & 7,795 & 0,86 & 0,11 \\
\hline Ingestão de matéria seca (\% PV) & 2,402 & 2,252 & 0,23 & 0,05 \\
\hline Ganho médio diário (GMD, $\mathrm{kg} \mathrm{dia}^{-1}$ ) & 1,487 & 1,511 & 0,18 & 0,67 \\
\hline Eficiência alimentar (kg GMD por kg IMS) & 0,180 & 0,194 & 0,02 & 0,09 \\
\hline
\end{tabular}

(1)EPM, erro padrão da média; P, significância estatística. 
Harvatine \& Allen (2006), quando alimentaram vacas leiteiras com dietas com sais de cálcio de ácidos graxos $(6,8 \%$ EE) como fonte de gordura. Putrino et al. (2006) também observaram redução da IMS $(2,15 \times 1,77 \% \mathrm{PV})$, ao fornecer dietas controle ( $3 \% \mathrm{EE})$ e com gordura protegida ( $6 \% \mathrm{EE})$ a bovinos Nelore em confinamento.

Esses trabalhos, que utilizaram gordura protegida, ajudam a evidenciar que os efeitos dos AGI sobre a IMS não estão relacionados somente aos problemas que podem ocasionar à degradabilidade ruminal, mas também decorrem de efeitos pós-absortivos. Allen (2000) concluiu que existe relação entre a adição de fontes de gorduras ricas em AGI na dieta de ruminantes e a redução da IMS. Além do efeito sobre a IMS, a maior absorção de AGI possivelmente melhorou a eficiência energética de síntese de tecidos e contribuiu para os valores semelhantes de GMD, peso vivo final, espessura de gordura e período médio de confinamento (Tabela 3).

As melhorias na eficiência energética podem ter contribuído também para o efeito quimiostático das gorduras sobre IMS. Segundo Krehbiel et al. (2006), o efeito quimiostático está relacionado ao ajuste do consumo de MS para manter constante a ingestão de energia. Assim, quando as exigências energéticas de mantença e ganho são atendidas, os animais passam a reduzir a IMS.

As médias de eficiência alimentar não foram influenciadas pelos tratamentos (Tabela 3). Respostas similares para GMD $\left(1,55 \times 1,40 \mathrm{~kg} \mathrm{dia}^{-1}\right)$, redução da IMS $\left(9,320 \times 8,230 \mathrm{~kg} \mathrm{dia}^{-1}\right)$ e eficiência alimentar $(0,160 \times 0,170 \mathrm{~kg}$ ganho por $\mathrm{kg}$ MS ingerida) de novilhos cruzados confinados foram observadas por Felton \& Kerley (2004a) ao avaliar dieta convencional $(4,8 \% \mathrm{EE})$ e com $16 \%$ de grãos de soja $(8,1 \% \mathrm{EE})$.
Jordan et al. (2006) também não detectaram diferenças significativas entre as médias de eficiência alimentar $(0,155 \times 0,168 \mathrm{~kg}$ ganho por $\mathrm{kg}$ MS ingerida) do tratamento controle $(3,9 \%$ EE) e com alto teor de gordura $(7,8 \% \mathrm{EE})$ ao fornecerem grãos de soja como fonte de gordura a novilhos confinados.

$O$ peso vivo inicial diferiu entre os animais dos diferentes grupos genéticos (Tabela 4). As variações nas médias de peso vivo no início do experimento eram esperadas, em razão das diferenças de idade e da massa corporal à desmama dos animais. Os animais Nelore eram dois meses mais jovens que os animais cruzados e Caracu, que apresentavam idades similares.

Não foram detectadas diferenças significativas entre as médias de peso vivo final dos animaisC-A-N, RA-C-N e Caracu (Tabela 4). Os animais Nelore apresentaram menor valor de peso vivo final. Os maiores valores de peso vivo final apresentados pelos animais cruzados e Caracu, em relação aos Nelore, provavelmente estão relacionados às diferenças existentes no potencial de crescimento desses animais.

Segundo Owens et al. (1993), animais de raças com maior tamanho corporal, como os animais cruzados e Caracu, avaliados neste experimento, apresentam maiores taxas de ganho de peso e peso vivo final por serem tardios na deposição de tecido adiposo. Porém, animais de menor tamanho corporal, como os animais Nelore, apresentam desempenhos inferiores e tendem a acumular gordura periférica com menor massa corporal, devido ao seu menor desenvolvimento muscular.

Essas características contribuem para que esses animais atinjam a espessura de gordura mínima exigida ( $3 \mathrm{~mm}$ ) com menores valores de massa corporal ao abate. Isso foi constatado neste experimento quando os valores de peso vivo final e espessura de gordura dos animais Nelore foram comparados aos de animais

Tabela 4. Peso vivo inicial e final, espessura de gordura, período de confinamento, ingestão de matéria seca, ganho médio diário e eficiência alimentar de bovinos de corte dos grupos genéticos Caracu, 1/2 Caracu 1/4 Angus 1/4 Nelore (C-A-N), 1/2 Red Angus $1 / 4$ Caracu $1 / 4$ Nelore (RA-C-N) e Nelore ${ }^{(1)}$.

\begin{tabular}{|c|c|c|c|c|c|c|}
\hline \multirow[t]{2}{*}{ Variáveis } & \multicolumn{4}{|c|}{ Grupos genéticos } & \multirow[t]{2}{*}{ EPM } & \multirow[t]{2}{*}{$\mathrm{P}$} \\
\hline & Caracu & $\mathrm{C}-\mathrm{A}-\mathrm{N}$ & RA-C-N & Nelore & & \\
\hline Peso vivo inicial (kg) & 219 & 266 & 231 & 194 & 21 & - \\
\hline Peso vivo final $(\mathrm{kg})$ & $472 \mathrm{a}$ & $484 a$ & $470 \mathrm{a}$ & $421 b$ & 33 & 0,03 \\
\hline Espessura de gordura (mm) & $3,87 \mathrm{ab}$ & $3,43 b$ & $3,83 b$ & $4,73 \mathrm{a}$ & 0,98 & 0,05 \\
\hline Período de confinamento (dias) & $185 \mathrm{a}$ & $135 b$ & $135 b$ & $189 \mathrm{a}$ & 28 & $<0,0001$ \\
\hline Ingestão de matéria seca $\left(\mathrm{kg} \mathrm{dia}^{-1}\right)$ & $7,96 b$ & $8,33 \mathrm{ab}$ & $8,79 \mathrm{a}$ & $7,05 \mathrm{c}$ & 0,86 & 0,002 \\
\hline Ingestão de matéria seca $(\% \mathrm{PV})$ & 2,29 & 2,27 & 2,50 & 2,25 & 0,23 & 0,06 \\
\hline Ganho médio diário (GMD, $\left.\mathrm{kg} \mathrm{dia}^{-1}\right)$ & $1,37 \mathrm{~b}$ & $1,69 \mathrm{a}$ & $1,78 \mathrm{a}$ & $1,16 \mathrm{c}$ & 0,18 & $<0,0001$ \\
\hline Eficiência alimentar (kg GMD por kg MS) & 0,17 & 0,19 & 0,20 & 0,17 & 0,02 & 0,07 \\
\hline
\end{tabular}

${ }^{(1)}$ Médias seguidas de letras iguais na mesma linha não diferem entre si pelo teste de Tukey, a 5\% de probabilidade. EPM, erro padrão da média; $\mathrm{P}$, significância estatística. 
cruzados. Os animais Nelore apresentaram maior espessura de gordura $(4,73 \pm 0,44 \mathrm{~mm})$ e menor peso ao abate $(421 \pm 14,84 \mathrm{~kg})$ em relação aos animais C-A-N e RA-C-N. O menor peso ao abate de animais Nelore em relação a taurinos e cruzados também foi observado por Euclides Filho et al. (2002) e Menezes \& Restle (2005).

Além do menor peso ao abate, os animais Nelore apresentaram menores valores de IMS $\left(\mathrm{kg} \mathrm{dia}^{-1}\right)$ e GMD em relação aos animais cruzados, fato que contribuiu para o maior tempo de permanência no confinamento (189 dias). Os animais C-A-N apresentaram GMD, IMS e período de confinamento similares aos dos animais RA-C-N. Ambos apresentaram GMD superiores aos dos animais Caracu.

Os menores valores de GMD dos animais Nelore podem estar associados à maior deposição de gordura na carcaça, geralmente observada na literatura (Jaeger et al., 2004; Fernandes et al., 2005). De acordo com Owens et al. (1993), animais de menor tamanho adulto depositam mais gordura na carcaça devido ao menor desenvolvimento muscular, e como a síntese de tecido adiposo é menos eficiente por não carrear água (Owens et al., 1995), isso pode contribuir para menores valores de GMD.

Os animais Nelore apresentaram IMS $\left(\mathrm{kg} \mathrm{dia}^{-1}\right)$ 20\% inferior em relação aos animais C-A-N e RA-C-N, e grande parte dessa diferença pode ser atribuída ao menor peso vivo médio dos Nelore. O menor peso vivo médio e o desempenho inferior dos animais Nelore foram observados por Menezes \& Restle (2005) ao confinar novilhos Charolês, Nelore e mestiços $3 / 4$ Charolês $1 / 4$ Nelore e $3 / 4$ Nelore $1 / 4$ Charolês. Os autores verificaram valores de PV médio de 338, 285, 353 e $371 \mathrm{~kg}$, IMS de 7,5, 6,5, 8,4 e $7,5 \mathrm{~kg} \mathrm{dia}^{-1}$ e GMD de 1,46, 0,98, 1,30 e 1,30 $\mathrm{kg} \mathrm{dia}^{-1}$ para os animais Charolês, Nelore, $3 / 4$ Charolês $1 / 4$ Nelore e $3 / 4$ Nelore $1 / 4$ Charolês, respectivamente.

Ao confinar animais $1 / 2$ Caracu $1 / 4$ Angus $1 / 4$ Nelore $\left(7,57 \mathrm{~kg} \mathrm{dia}^{-1}\right), 1 / 2$ Caracu $1 / 4$ Simental $1 / 4$ Nelore $\left(7,97 \mathrm{~kg} \mathrm{dia}^{-1}\right)$ e Nelore $\left(6,47 \mathrm{~kg} \mathrm{dia}^{-1}\right)$, Euclides Filho et al. (2002) também observaram valores inferiores de IMS e GMD dos animais Nelore em relação aos animais cruzados, assim como Euclides Filho et al. (2003), quando avaliaram desempenho em confinamento de animais $1 / 2$ Canchim $1 / 4$ Simental $1 / 4$ Nelore e Nelore, verificaram menores médias de GMD $(1,30 \times 1,69 \mathrm{~kg}$ $\left.\mathrm{dia}^{-1}\right)$ e de IMS $\left(8,25 \times 7,61 \mathrm{~kg}\right.$ dia $\left.^{-1}\right)$ dos animais Nelore em relação aos animais $1 / 2$ Canchim $1 / 4$ Simental $1 / 4$ Nelore, respectivamente.
$\mathrm{Na}$ ausência de restrições nutricionais, como no caso deste experimento, as diferentes médias de IMS observadas entre os grupos genéticos provavelmente estão associadas às distintas exigências de mantença e produção dos animais. O National Research Council (1996) cita que animais provenientes de cruzamentos possuem maior exigência nutricional e maior capacidade de consumo para manter taxas de ganho superiores em relação a animais puros.

Outro fator que contribui para o desempenho superior de animais cruzados é a heterose, que se manifesta em boas condições alimentares e promove a obtenção de animais de maior tamanho e maior exigência nutricional (Restle et al., 2000). Dessa forma, em função do maior potencial genético de crescimento, os animais cruzados têm maior exigência nutricional, que resulta em maior ingestão de alimentos. Logo, a superioridade para GMD - e, consequentemente, a maior IMS - observada nos animais C-A-N e RA-C-N era esperada.

Independentemente da proporção de sangue europeu adaptado nos dois cruzamentos testados neste trabalho, os animais apresentaram desempenhos semelhantes. Porém, ao se avaliar os resultados dos animais cruzados e de Caracu puros, verifica-se que não houve diferenças de IMS entre os C-A-N e os Caracu.

Um fator que pode ter contribuído para este resultado é a proporção de sangue adaptado, influenciado não só pelos genes dos animais Caracu, mas também pelo dos animais Nelore. Levando em consideração a participação dos animais Nelore (25\%) e Caracu (50\%) no cruzamento, os animais C-A-N continham no total $75 \%$ de sangue adaptado, proporção próxima do Caracu puro (100\% adaptado). Além da adaptabilidade, também predominava sangue europeu nos animais C-A-N (75\%).

Logo, os animais desses dois grupos genéticos possivelmente apresentaram exigência nutricional semelhante, o que resultou em médias similares de IMS e peso vivo final. Já quando os animais RA-C-N e Caracu foram comparados, verificou-se que os primeiros apresentaram melhores desempenhos.

Segundo Arrigoni et al. (2004), vários trabalhos que estudaram desempenho de bovinos cruzados oriundos de zebuínos e europeus verificaram maior taxa de crescimento e melhor aproveitamento dos alimentos em animais com maior percentagem de sangue europeu, principalmente ao se utilizar bovinos da raça Aberdeen Angus no cruzamento. 
Os animais Angus provavelmente aproveitam melhor a energia metabolizável da dieta para ganho de massa corporal, devido à sua exigência de mantença menor (National Research Council, 1996) quando comparada à de animais de cruzamentos contendo raças de maior tamanho corporal, como a raça Caracu, por exemplo. Essa justificativa ajuda a explicar o melhor desempenho dos animais RA-C-N, pois nesse cruzamento havia $50 \%$ de sangue Angus.

Não foram observadas diferenças significativas entre as médias de IMS em \% PV, tempo de confinamento e espessura de gordura dos animais Caracu e Nelore (Tabela 4). As médias de IMS em \% PV similares dos animais Caracu e Nelore não eram esperadas e, em parte, devem-se ao grande efeito de um animal Caracu que teve valor de desempenho muito inferior ao dos demais, fato que contribuiu para a redução da média do grupo.

A similaridade no tempo de confinamento e na espessura de gordura dos animais Nelore e Caracu ocorreu devido ao GMD significativamente superior apresentado pelos animais Caracu, fato que resultou em peso vivo final significativamente maior $(472 \times 421 \mathrm{~kg})$. Não foram observadas diferenças entre as médias de eficiência alimentar dos quatro grupos genéticos.

\section{Conclusões}

1. A dieta com alto teor de gordura pode ser utilizada na alimentação de tourinhos $1 / 2$ Caracu $1 / 4$ Angus $1 / 4$ Nelore, para melhorar o desempenho em confinamento.

2. A dieta com alto teor de gordura é eficiente para reduzira ingestão de matéria seca sem prejudicar o ganho de massa corporal dos tourinhos no confinamento.

\section{Agradecimentos}

À Fundação de Apoio ao Desenvolvimento do Ensino, Ciência e Tecnologia do Estado de Mato Grosso do Sul, pela concessão da bolsa; à Embrapa Gado de Corte, pelo suporte à pesquisa, e ao Conselho Nacional de Desenvolvimento Tecnológico, pelo auxílio financeiro.

\section{Referências}

AFERRI, G.; LEME, P.R.; SILVA, S. da L. e; PUTRINO, S.M.; PEREIRA, A.S.C. Desempenho e características de carcaça de novilhos alimentados com dietas contendo diferentes fontes de lipídios. Revista Brasileira de Zootecnia, v.34, p.1651-1658, 2005.
ALLEN, M.S. Effects of diet on short-term regulation of feed intake by lactating dairy cattle. Journal of Dairy Science, v.83, p.1598-1624, 2000.

AOAC INTERNATIONAL. Official methods of analysis. $15^{\text {th }} \mathrm{ed}$. Washington: AOAC International, 1990. 1141p.

ARRIGONI, M. de B.; ALVES JÚNIOR, A.; DIAS, P.M.A.; LUDOVICO, C.; CERVIERI, R. da C.; SILVEIRA, A.C.; OLIVEIRA, H.N. de; CHARDULO, L.A.L. Desempenho, fibras musculares e carne de bovinos jovens de três grupos genéticos. Pesquisa Agropecuária Brasileira, v.39, p.1033-1039, 2004.

CHILLIARD, Y. Dietary fat and adipose tissue metabolism in ruminants, pigs, and rodents: a review. Journal of Dairy Science, v.76, p.3897-3931, 1993.

EUCLIDES FILHO, K.; FIGUEIREDO, G.R. de; EUCLIDES, V.P.B.; SILVA, L.O.C. da; CUSINATO, V.Q. Eficiência bionutricional de animais da raça Nelore e seus mestiços com Caracu, Angus e Simental. Revista Brasileira de Zootecnia, v.31, p.331-334, 2002.

EUCLIDES FILHO, K.; FIGUEIREDO, G.R. de; EUCLIDES, V.P.B.; SILVA, L.O.C. da; ROCCO, V.; BARBOSA, R.A.; JUNQUEIRA, C.E. Desempenho de diferentes grupos genéticos de bovinos de corte em confinamento. Revista Brasileira de Zootecnia, v.32, p.1114-1122, 2003.

FELTON, E.E.D.; KERLEY, M.S. Performance and carcass quality of steers fed different sources of dietary fat. Journal of Animal Science, v.82, p.1794-1805, 2004a.

FELTON, E.E.D; KERLEY, M.S. Performance and carcass quality of steers fed whole raw soybeans at increasing inclusion levels. Journal of Animal Science, v.82, p.725-732, 2004b.

FERNANDES, H.J.; PAULINO, M.F.; MARTINS, R.G.R.; VALADARES FILHO, S. de C.; TORRES, R. de A.; PAIVA, L.M.; RIBEIRO, V.A. Crescimento de componentes corporais de três grupos genéticos na fases de recria e terminação. Revista Brasileira de Zootecnia, v.34, p.288-296, 2005.

FERREIRA, I.C.; SILVA, M.A.; REIS, R.P.; EUCLIDES FILHO, K.; FIGUEIREDO, G.R. Análise de custos de diferentes grupos genéticos de bovinos de corte terminados em confinamento. Arquivo Brasileiro de Medicina Veterinária e Zootecnia, v.56, p.385-391, 2004.

HARVATINE, K.J.; ALLEN, M.S. Effects of fatty acid supplements on feed intake, and feeding and chewing behavior of lactating dairy cows. Journal of Dairy Science, v.89, p.1104-1112, 2006.

JAEGER, S.M.P.L.; DUTRA, A.R.; PEREIRA, J.C.; OLIVEIRA, I.S.C. de. Características da carcaça de bovinos de quatro grupos genéticos submetidos a dietas com ou sem adição de gordura protegida. Revista Brasileira de Zootecnia, v.33, p.1876-1887, 2004.

JENKINS, T.C. Lipid metabolism in the rumen. Journal of Dairy Science, v.76, p.3851-3863, 1993.

JORDAN, E.; KENNY, D.; HAWKINS, M.; MALONE, R.; LOVETT, D.R.; O'MARA, F.P. Effect of refined soy oil or whole soybeans on intake, methane output, and performance of young bulls. Journal of Animal Science, v.84, p.2418-2425, 2006. 
KREHBIEL, C.R.; CRANSTON, J.J.; MCCURDY, M.P. An upper limit for caloric density of finishing diets. Journal of Animal Science, v.84, p.34-49, 2006.

LANNA, D.P.D.; ALMEIDA, R.; NEPOMUCENO, N. RLM 3.0: ração de lucro máximo. Versão 3.0. Piracicaba: Esalq/USP, 2005.

MARTINEZ MARÍN, A.L. Influencia de la nutrición sobre el contenido y tipo de ácidos grasos en la carne de los rumiantes. Archivos de Zootecnia, v.56, p.45-66, 2007.

MCNIVEN, M.A.; DUYNISVELD, J.; CHARMLEY, E.; MITCHEL, A. Processing of soybean affects meat fatty acid composition and lipid peroxidation in beef cattle. Animal Feed Science and Technology, v.116, p.175-184, 2004.

MENEZES, L.F.G. de; RESTLE, J. Desempenho de novilhos de gerações avançadas do cruzamento alternado entre as raças Charolês e Nelore, terminados em confinamento. Revista Brasileira de Zootecnia, v.34, p.1927-1937, 2005.

MIR, P.S.; MEARS, G.L; MIR, Z. Vegetable oil in beef cattle diets. In: BEAUCHEMIN, K.A.; CREWS, D.H. (Ed.). Advances in beef cattle science. Lethbridge: Lethbridge Research Centre, 2001. v.1, p.88-104.

NATIONAL RESEARCH COUNCIL. Nutrient requirements of beef cattle. $7^{\text {th }}$ ed. Washington: National Academic Press, 1996. 242p.

OBICI, S.; FENG, Z.H.; MORGAN, K.; STEIN, D.; KARKANIAS, G.; ROSSETI, L. Central administration of oleic acid inhibits glucose production and food intake. Diabetes, v.51, p.271-275, 2002.
OWENS, F.N.; DUBESK, P.; HANSON, C.F. Factors that alter the growth and development of ruminants. Journal of Animal Science, v.71, p.3138-3150, 1993.

OWENS, F.N.; GILL, D.R.; SECRIST, D.S.; COLEMAN, S.W. Review of some aspects of growth and development of feedlot cattle. Journal of Animal Science, v.73, p.3152-3172, 1995.

PALMQUIST, D.L. The role of dietary fats in efficiency of ruminants. Journal of Nutrition, v.124, p.1377-1382, 1994.

PUTRINO, S.M.; LEME, P.R.; SILVA, S. da. L. e; ALLEONI, G.F.; LANNA, D.P.D.; GROSSKLAUSS, C. Exigências líquidas de proteína e energia para ganho de peso de novilhos Nelore alimentados com dietas contendo grão de milho úmido e gordura protegida. Revista Brasileira de Zootecnia, v.35, p.301-308, 2006.

RESTLE, J.; ALVES FILHO, D.C.; FARTURI, C.; ROSA, J.R.P.; PASCOAL, L.L.; BERNARDES, R.A.C.; KUSS, F. Desempenho na fase de crescimento de machos bovinos inteiros ou castrados de diferentes grupos genéticos. Revista Brasileira de Zootecnia, v.29, p.1036-1043, 2000.

SAS INSTITUTE. SAS/STAT: guide for personal computers. Cary: SAS Institute, 2002.

WEISS, W.P.; CONRAD, H.R.; ST. PIERRE, N.R. A theoretically-based model for predicting total digestible nutrient values of forages and concentrates. Animal Feed Science and Technology, v.39, p.95-110, 1992.

Recebido em 6 de novembro de 2008 e aprovado em 27 de junho de 2009 